\title{
O pesquisador de fronteira e outras subjetivações: uma questão de método
}

\section{The frontier researcher and other subjectivities: a matter of method}

\section{El investigador de frontera $y$ otras subjetividades: una cuestión de método}

\section{Maria Aparecida dos Santos*}

Universidade Federal Fluminense - UFF, Niterói, Rio de J aneiro, Brasil

\begin{abstract}
RESUMO
O objetivo geral deste artigo é cartografar caminhos e vicissitudes do pesquisador de fronteira, aquele que, encarnado na sua pesquisa, assume politicamente sua posição de buscar novos caminhos textuais para suas reflexões acerca da ciência e de suas práticas, incluindo a questão do método. Inspirada na Teoria do Ator-Rede, sigo pistas dos actantes envolvidos na entrada das terapias naturais, integrativas e complementares no Sistema Único de Saúde - SUS brasileiro. Pergunto como é pesquisar na fronteira e reflito sobre as subjetivações produzidas no processo de pesquisar desse lugar inquietante.
\end{abstract}

Palavras-chave: fronteira, teoria do ator-rede, terapias naturais, integrativas e complementares no SUS.

\begin{abstract}
The general goal of this article is to map the frontier researcher's routes and changes. By frontier researcher, I mean the professional that, totally involved in his/her research, publicly assumes his/her political stand of looking for new concrete routes for his/her reflexions on science and its practices, including the matter of method. Inspired by the Actor Network Theory (ANT), I follow the tracks made by acting agents involved in the introduction of natural, integral and complementary therapies in the Brazilian Integrated Health System (SUS). I raise the question of how it is to do research at the frontier and ponder on the subjectivities produced in the process of researching from this instigating point.
\end{abstract}

Keywords: researcher's routes, actor network theory, natural, integral and complementary therapies in the Brazilian Integrated Health System.

\section{RESUMEN}

El objetivo general de este trabajo consiste entrazar el camino y vicisitudes del investigador de frontera. Llamo investigador de frontera al profesional que, totalmente involucrado em su investigación, asume publicamente su posición política de buscar nuevos y concretos horizontes para sus reflexiones sobre La ciencia y sus prácticas, incluyendo la cuestión del método. Inspirada por la Teoría Actor-Red, acompaño los trazos dejados por 
los agentes actuantes involucrados en la introducción de las terapias naturales, integrales y complementares en el sistema único de salud brasileño (SUS). Presento la cuestión sobre cómo es el acto de hacer investigaciones en la frontera y hago una reflexión sobre las subjetividades en ese proceso a partir de tal punto inquietante.

Palabras clave: investigación de vanguardia, teoría del actor-red, terapias naturales, complementarias y de integración en el Sistema Único de Salud de Brasil.

\section{I ntrodução}

Imaginar novos caminhos textuais para reflexões acerca da ciência e de suas práticas passa por entender o mundo e transladar o conhecimento, a partir de novas gramáticas. Para Ferreira (1999), a gramática do grego transliterado grammatiké, feminino substantivado de grammatikós, é a "arte de ler e de escrever", pelo latim grammatica, com o mesmo significado em Eckersley e Macaulay (1995), "é a arte de colocar as palavras certas nos lugares certos". No entanto, no movimento de tessitura da escrita nem sempre a sintaxe se opera de modo assim tão preciso. Muitas vezes, no exercício que aqui se opera, somos tocados por seus movimentos, experimentando efetivamente que, como diz Deleuze \& Parnet (1998), “há apenas palavras inexatas para designar alguma coisa exatamente" (p.11). Portanto, colocar palavras, fazer novas leituras, pensar por outras epistemologias e produzir novos modos de escritas fazem parte da minha proposta de pesquisa.

O objetivo geral deste ensaio é cartografar caminhos e vicissitudes do pesquisador de fronteira, aquele que, encarnado na sua pesquisa, assume politicamente sua posição de "pesquisar com" ${ }^{1}$ e imagina novos caminhos textuais para suas reflexões acerca da ciência e de suas práticas. Se a produção objetiva das pesquisas em rede se dá na conexão do conhecimento com a prática e esta toma potência nas fronteiras, pergunto: como é pesquisar na fronteira?

No meu doutorado ${ }^{2}$, sigo pistas dos actantes envolvidos na entrada das terapias naturais, integrativas e complementares no Sistema Único de Saúde - SUS brasileiro. Para Bruno Latour (2012b), ator é tudo que age, deixa traço, produz efeito no mundo, podendo se referir a pessoas, instituições, coisas, animais, objetos, máquinas. Ator não se refere apenas aos humanos, mas também aos não humanos. Por esse motivo Latour (2001) sugere o termo actante: “(...) uma vez que, em inglês, a palavra actor (ator) se limita a humanos, utilizamos muitas vezes actant (actante), termo tomado à semiótica para incluir não- humanos na definição" (p. 346).

Parto do princípio proferido por Mol (2008) e Law (2004), de que diferentes práticas tendem a produzir diferentes realidades. Diante disso, necessariamente o pesquisador de fronteira se interessa por 
haveres entre as ações que criarão realidades, ou seja, as conexões parciais e não centrais ou totais. Para tanto, o projeto de pesquisar da fronteira abre espaço para valorar e olhar para outras práticas (no caso da saúde) mais culturais e mestiças, que neste momento fazem parte do sistema único de saúde do Brasil, mas, não se encaixam no pacote padrão da biomedicina. Parto como proposta de pesquisa enxergar como as coisas são rearranjadas, escolhidas, acolhidas ou excluídas nas pesquisas e nas práticas de cuidado em saúde.

Pesquiso na fronteira entre a prática hegemônica da biomedicina com foco na medicalização para remissão da doença e as terapias naturais, com foco na ação do desbloqueio e/ou estímulo das forças vitais para manutenção da capacidade do próprio corpo manter-se são. Para Law (2004), a fronteira é um espaço instável, mutável, um ponto provisório de encontro de mundos distintos, de forças geradoras e relacionais, sempre sob tensão, onde, justamente por isso possibilita produzir relações pulsantes e vivas, novas realidades e novas versões de mundo (p.4). Ao habitar essa fronteira, busco novas versões (Despret, 2001) acompanhamos seus tensionamentos mais proximamente: às vezes a passagem é porosa, e há entre essas formas complementares de cuidar muitas vias de atravessamento. Outras vezes, no entanto, a fronteira é tão impermeável que sequer podemos acompanhar a possibilidade de interferências mútuas se operando no concreto das práticas de cuidado e saúde.

Sigo a inspiração da Teoria do Ator-Rede de Latour (2012b), que nos leva a pesquisar um objeto em ação, que se dá em rede, na conexão entre conhecimento e prática, se complementando na ideia de Haraway (1995), que sugere ser nas fronteiras que se delimitam e instauram o que conta ou não como objetividade. Nesse lugar de fronteira pesquiso lançando mão de algumas ferramentas, como revisão bibliográfica sobre terapias oriundas de cosmovisão diferenciada - principalmente terapias orientais -, análise de documentos, análise dos usos de materiais, cuidados e tecnologias (moxa, agulha de acupuntura, massagem shiatsu, tui-na, sementes de mostarda, etc.), e suas subjetivações produzidas em usuários e técnicos envolvidos no processo. Pesquiso esse campo por interesse em criar mundo, em fazê-lo variar, pois aposto em novas possibilidades de inscrever na saúde e nas práticas de cuidado em saúde um outro trato, longe do destrato descuidado, que pode estar em qualquer forma de trato. Como sugere Santos (2002), perto de outras gramáticas possíveis, alternativas, mais perto da fronteira e mais afastado do centro, para melhoria de condições do atendimento de quem depende do sistema público de saúde.

Para conversarmos inspiro-me em Haraway (1995), que aposta nas práticas, na ação do conhecimento como um nódulo condensado num campo de poder agonístico, encarnado, corporificado, localizado, responsável (p. 10). Essa autora não aceita uma teoria forjada de 
poderes inocentes para representar o mundo. Prefere que se nomeie onde se está e onde não se está aliado. Ela acredita que a objetividade tenha uma perspectiva parcial, específica e, dessa maneira, possibilita abrir a questão da responsabilidade sobre a geração de conhecimento e criação de mundo (p. 26). Por sua vez, Stengers (1998) concorda que especificar "onde estamos e onde não estamos" cria uma oportunidade de conexões com outros vieses divergentes, possibilita falar do "outro inapropriado" (p. 10-11). Esta proposta, este modo de operar é potencializado quando se dá na fronteira, por isso inspiro-me igualmente em Boaventura de Sousa Santos, para quem:

A fronteira enquanto espaço, está mal delimitada, física e mentalmente (...). Por este motivo, a inovação e a instabilidade são, nela, as duas faces das relações sociais. (...) Espaço provisório e temporário, onde as raízes se deslocam tão naturalmente como o solo que as sustenta. (...) Viver na fronteira significa viver fora da fortaleza; significa prestar atenção a todos os que chegam e aos seus hábitos diferentes e reconhecer na diferença as oportunidades para 0 enriquecimento mútuo (Santos, 2001, p.349).

Para mapear como e quem decide quem fica de fora da ciência, o pesquisador segue em movimentos de composição e rodeio, de idas e vindas, ao redesenhar a todo momento a área investigada, de permanentes ajustes (negociações). A saber, John Law (2004), argumenta que na prática, a pesquisa precisa ser mais impura, diversificada, mais variada. Isso porque é dessa maneira como a maior parte do mundo é. Pois, há múltiplas versões sobre a mesma realidade, muitos termos heterogêneos que comportam as fronteiras. Todo esse processo e disponibilidade expõe o pesquisador a novas condições e produções de subjetividades; ele vai se transmutando com as evidências produzidas no processo da pesquisa.

\section{Como é pesquisar na fronteira? Novas produções de subjetividades no pesquisador}

$\mathrm{Na}$ areia movediça, quanto mais você luta, mais você afunda; mas como seu corpo é menos denso do que ela, basta relaxar para flutuar 3. O segredo é não entrar em pânico, nem precipitar uma reação afoita. A maior parte das pessoas que afundam na areia movediça ou em qualquer outro tipo de líquido é formada por aquelas que entram em pânico e começam a se debater. Assim deve operar o pesquisador de fronteira: aprender a flutuar, a sentir a textura e as rugosidades da areia, em vez de entrar em pânico ou se afobar. 
Venho estudando e atuando na acupuntura e terapêuticas naturísticas há cerca de trinta anos. Nesse tempo, colhendo filosofias orientais, meu olhar foi marcado por uma cosmovisão bem diferente da que hegemonicamente se estabeleceu como cultura ocidental. A saúde, principalmente, seria uma questão de respirar o ar e o prana (energia da vida solta no ar) profundamente, de meditar e afastar os pensamentos ruins e de apego, dançar, praticar movimentos circulares do tai-chi, comer alimentos vivos, escutar música boa para o espírito, manter boa relação com os elementos da natureza (terra, madeira, fogo, ar e água) e, no caso de desequilíbrio, buscar algum auxílio no estímulo de pontos da acupuntura com agulhas, moxa, sementes de mostarda, e chamar a atenção do corpo para o restabelecimento da energia vital. Com apreço ao conhecimento brasileiro sobre saúde, dos caiçaras, índios, caboclos e negros, também bebi da sabedoria da fitoterapia e cuidados brasileiros (óleo de copaíba, unguentos, cataplasmas, sucos nutridores). Minha bisavó era parteira no Pará, recebeu todos os filhos de sua filha em casa e por suas mãos. Minha mãe quando menina teve crupe (doença infectocontagiosa grave) e foi desenganada pelos médicos para ser curada com embrocações (pinceladas direto na garganta e amígdalas) de óleo de copaíba feitas pela avó; meu tio paterno, médico, experimentava em mim aplicações de acupuntura quando eu tinha 7 anos de idade; minha avó paterna aplicava cromoterapia nos pacientes com bronquite. Assisti algumas vezes ao visitar o consultório do tio em São Paulo ao trabalho que fazia com acupuntura em dependentes químicos. Todos sentados em cadeiras no corredor interno da clínica, com agulhas implantadas na pele ligadas a eletrodos (estimulando os pontos para liberar mais serotonina e endorfinas). Muito aprendizado e curiosidade me educaram nessa área de saúde alternativa.

Esses mais de trinta anos de terapeuta naturista foram tempos difíceis, em luta constante, vivendo na margem, na fronteira, uma profissional de saúde excluída do sistema de saúde da população do seu país e muitas vezes apontada coma charlatã, ainda que, cuidando de uns e de outros com afinidades de visão. Carvalho (2005) esclarece que no período dos anos 1950 a 1980 ocorreram mudanças culturais significativas quanto aos hábitos e valores vigentes na sociedade brasileira. Transformações na estrutura produtiva formando de maneira crescente uma "sociedade de consumo", com desdobramentos na área da saúde, aplicando uma reeducação da população com vistas a incorporar novos hábitos e práticas próprios da medicina erudita, ortodoxa. Dessa maneira, a repressão visando a expropriação das práticas populares de saúde inclui a criminalização e a inclusão do termo "curandeirismo" aos terapeutas de fora da biomedicina (p. 12). Madel Luz (1988) traduz o "charlatão" como essa figura desviante moral e herética da ciência, criação do século 
da razão. Termo fundado no final do século XVIII, momento em que as academias e as escolas das universidades europeias tinham 0 poder de colocar sobre uma teoria o selo da verdade, elevando seu autor socialmente, em termos políticos e econômicos, ou, pelo contrário, desqualificando-o junto à sociedade, às cortes e aos governos. É o pior epíteto que um cientista pode ouvir, pois implica desmoralização e perda de status social e profissional (p. 120). Dessa maneira, segui minha arte, arte de cuidar, assim clandestinamente, não querendo aparecer, mais silenciosa, sem jamais ter deixado de estudar e atender. Havia um medo de ser acusada, de ser presa, mas pensava - se for presa cuidarei das pessoas presas, não muda muita coisa. Entretanto, isso nunca aconteceu, e acho mais difícil acontecer agora. Segui fazendo política, criando mundo, influenciando, contagiando pessoas com essa ideia de cuidado mais afastado da industrialização química, mais longe do viés hospitalocêntrico e mais perto do respeito à natureza, à Terra, ao planeta. Levei meus cuidados por vários estados do Brasil, ensinei aos médicos do Instituto Hannemaniano do Brasil ${ }^{4}$ e aos médicos homeopatas em um congresso em Padova, na Itália ${ }^{5}$. Os passos seguintes eram sempre repensados, se expor ou não se expor, gritar ou silenciar, e achei que o silêncio esguio, ardiloso, arteiro e tranquilo daquele que estava na região de fronteira, mas que contagiava, seria a melhor estratégia a seguir. E, assim, chego à academia, devagar, sem a pressa dos jovens e escrevo no TCC sobre uma possível aproximação das terapias complementares com a psicologia ${ }^{6}$; meu mestrado fala de medos e saúde dentro de um lugar de terapias naturais ${ }^{7}$; uma especialização em psicossomática e cuidados transdisciplinares com o corpo me permite escrever no trabalho de conclusão uma genealogia e arqueologias das terapias alternativas entrando no SUS e, no doutorado, aprofundando as subjetivações produzidas em usuários e técnicos por esse serviço prestado no SUS. A aflição de ser uma clandestina nunca saiu de perto. No entanto, Michel Foucault (1979) foi meu parceiro quando me fez encarnar a ideia da resistência, da micropolítica ${ }^{8}$ e microrrevoluções. Nas relações de poder, há necessariamente uma relação de forças, em que sempre há a possibilidade de resistência, pois, se não houver possibilidade de resistência, de resistência violenta, de fuga, de subterfúgios, de estratégias que invertam a situação, não haverá de forma alguma relações de poder (p. 61).

Para Deleuze \& Parnet (1998), "sobre as linhas de fuga só pode haver uma coisa, a experimentação-vida" (p. 39). Pensando com Foucault, compreendi melhor meu caminhar quando me dei conta que:

(...) verdade é o conjunto das regras segundo as quais se distingue $o$ verdadeiro do falso e se atribui aos verdadeiros efeitos específicos de poder; entendendo-se também que não 
se trata de um combate em favor da verdade, mas em torno do estatuto da verdade e do papel econômico-político que ela representa (Foucault, 1979, p. 13).

Como fiz o caminho inverso dos colegas acupunturistas da academia pós-graduados, ou seja, fui estudar a filosofia oriental nas medicinas chinesa, indiana, tibetana, japonesa e suas cosmovisões e práticas terapêuticas, antes de entrar para a academia, experimentei tensão constante. Primeiro por ser considerada "charlatã", "curandeira", por não ter títulos acadêmicos; depois por estar falando de algo diferente, ainda desconhecido da grande maioria da academia, portanto duvidoso. Quando Foucault transbordou seus escritos nos meus olhos, tive momentos de paz e certeza de que estava no caminho certo: o meu caminho, aquele que escolhi percorrer desde muito cedo, numa guerra silenciosa, num exercício de poder de tensão constante, buscando fazer microrrevoluções, principalmente na esfera da saúde das pessoas e minha própria. Essas microrrevoluções dizem do acesso e experimentação de outras formas de cuidado, de estar com e de outros modos. Não se tratava de fugir da medicina hegemônica e tradicional como uma maneira de "bater em retirada". Pelo contrário, como se refere Deleuze \& Parnet (1998), "fugir não é renunciar às ações. Não há nada mais ativo que uma fuga. Fugir é fazer um sistema vazar, é traçar linhas, toda uma cartografia. Só se descobrem mundos através de uma longa fuga quebrada" (p. 49).

Um longo caminho controverso entre ser louco, em um momento aquele que supostamente rejeita a biomedicina e o progresso farmacológico; ser alternativo à biomedicina, em um segundo momento; ser complementar à biomedicina em um terceiro momento; e, no momento atual, ser uma respeitável terapeuta natural, integrativa e complementar à biomedicina hegemônica. Hoje, com a entrada dessa cosmovisão diferenciada de saúde no SUS, os editais do CNPq estimulam a pesquisa sobre tais abordagens.

Edital de Chamada MCTI/CNPq/MS - SCTIE - Decit № 07/2013, o presente interessamento do Ministério da Ciência, da Tecnologia e Inovação - MCTI, por intermédio do Conselho Nacional de Desenvolvimento Científico e Tecnológico - CNPq, e do Ministério da Saúde - MS no desenvolvimento de pesquisas sobre as Práticas Integrativas e Complementares (PICs) no Sistema Único de Saúde (SUS), considerando: Medicina Tradicional Chinesa/Acupuntura e técnicas derivadas em conformidade com a Política Nacional de Práticas Integrativas e Complementares (PNPIC) no SUS. 
Como "pensadora clandestina" medito agora - o que eles querem: nos aprisionar nas paredes do Estado e nos fazer desaparecer? Talvez, mas o que eu posso agora é continuar silenciosa e ativar reflexões. Logo, o pesquisador de fronteira precisa, antes de tudo, se acostumar a ser um nômade, um desterritorializado por excelência. Como pesquisadora de fronteira, pergunto quais vínculos e negociações são fabricadas no campo de pesquisa?

$\mathrm{O}$ pesquisador de fronteira tem de ser meio nômade, porque a terra se desterritorializa debaixo dos seus pés, a terra se move, e o pesquisador se reterritorializa por alguns instantes, em um suporte momentâneo para pensar sua pesquisa, pensar seu olhar e intervir sobre aquele território. O nômade se distribui em um espaço liso, ele ocupa, habita, mantém esse espaço, e aí reside seu princípio territorial. O espaço nômade é liso, porque é marcado apenas por "traços" que se apagam e se deslocam com o trajeto.

Em um espaço liso heterogêneo, abriga um tipo muito particular de multiplicidades: as multiplicidades assimétricas, descentradas, rizomáticas, que ocupam o espaço sem "medi-lo", e que só se pode explorar "avançando progressivamente", tateando. Como então esse pesquisador que traz em si essa vontade nômade, produz a realidade que vai parecer algo que não se apaga e passa a ser uma versão existente? Sem dúvida,um grande desafio para os nômades, para todo pesquisador.

Para Deleuze e Guattari:

O nômade não tem pontos, trajetos, nem terra, embora evidentemente ele os tenha. Se o nômade pode ser chamado de o Desterritorializado por excelência, é justamente porque a reterritorialização não se faz depois, como no migrante, nem em outra coisa, como no sedentário (com efeito, a relação do sedentário com a terra está mediatizada por outra coisa, regime de propriedade, aparelho de Estado...). Para o nômade, ao contrário, é a desterritorialização que constitui sua relação com a terra, por isso ele se reterritorializa na própria desterritorialização. É a terra que se desterritorializa ela mesma, de modo que o nômade aí encontra um território. A terra deixa de ser terra, e tende a tornar-se simples solo ou suporte. A terra não se desterritorializa em seu movimento global e relativo, mas em lugares precisos, ali mesmo onde a floresta recua, e onde a estepe e o deserto se propagam. (...) No espaço liso do Zen, a flecha já não vai de um ponto a outro, mas será recolhida num ponto qualquer, para ser relançada a um ponto qualquer, e tende a permutar com o atirador e o alvo (Deleuze \& Guattari, 1997, p.38). 
A noção de rede da Teoria do Ator-Rede se aproxima da noção de rizoma, elaborada por Deleuze (1995), que propõe um fluxo diferente do modelo da árvore ou da raiz, que fixam um ponto, uma ordem. No rizoma, qualquer ponto pode ser conectado a qualquer outro. De acordo com os autores de Mil platôs, no rizoma não há unidade, apenas agenciamentos; não há pontos fixos, apenas linhas, e o mesmo acontece na Teoria do Ator-Rede. Márcia Moraes (2000) compara uma rede a uma totalidade aberta, capaz de crescer em todos os lados e direções, como um rizoma, sendo seu único elemento constitutivo o nó, o encontro, a conexão. A palavra "rede" indica que os recursos estão concentrados em poucos locais - nas laçadas interligando fios e malhas. Para Latour (2000), essas conexões transformam os recursos esparsos numa teia que parece se estender por toda parte (p. 294).

Para o pesquisador da Teoria do Ator-Rede, faz parte do seu cotidiano de investigação tatear, "mapear as redes sóciotécnicas e seguir pistas propiciadas por actantes agindo dentro de uma rede, e se caracteriza pela maneira particular por onde define os outros actantes aos quais ele se liga e faz conexões" (Latour, 2001, p. 346). Para encontrar o que realmente interessa (inter-esse) é preciso saber coexistir como nômade, na área de fronteira, mutável, invisível, pouco explorada, caótica e conspirar com as controvérsias criando pontes. Tal disposição exige um estilo de pesquisador que vai ao encontro do desconhecido com jeito enamorado, se implicando com as evidências e principalmente com aquilo que não está aparente. Às vezes, como no texto de Guimarães Rosa, se postando na terceira margem do rio, no limbo entrefronteiras, lugar onde, aparentemente, seria o seu fim. E de lá enxergar o que acontece nas fronteiras: negociações, sempre políticas. Dessa subjetivação mutante que se dá com o pesquisador de fronteira advêm possibilidades de novas gramáticas, as formas alternativas de conhecimento.

As formas alternativas de conhecimento, segundo Santos (2001), acontecem nas periferias que estão menos engessadas pelo poder central e com isso geram práticas sociais alternativas e vice-versa ( $p$. 344). Observe o que diz a política brasileira sobre o que é habitar nas faixas de fronteira:

Apesar de (...) o território nacional em 11 estados e 588 municípios reunir cerca de 10 milhões de habitantes, a Faixa de Fronteira configura-se como uma região pouco desenvolvida economicamente, historicamente abandonada pelo Estado, marcada pela dificuldade de acesso a bens e serviços públicos, pela falta de coesão social, pela inobservância de cidadania e por problemas peculiares às regiões fronteiriças. Isso determinou a diretriz específica de desenvolvimento dessa região na PNDR (PDFF, 2007, p. 8) 
Apesar da ideia de "falta de coesão social" evidenciada no documento brasileiro, pesquisadores de fronteira, como nós e Boaventura Santos, enxergamos nesse lugar, por exigência da sobrevivência, pessoas que agem coletivamente e se relacionam entre coletivos, coletivos que tendem a aprender a ouvir e observar as diferenças, se afastando da herança e memória hegemônica, por não fazer parceria com ela. O lugar é aberto à criação.

As periferias são zonas de fronteira, e, como define John Law (2004), olhar para a fronteira sugere olhar para a negociação, porém fronteira é local de conflito, onde se encontram controvérsias, não é um lugar cômodo. O que tomo por lugar cômodo é aquele em que aparentemente tudo está estabilizado, seguro e, portanto, pouca energia de trabalho é mobilizada para criar; enfim, um lugar previsível. A fronteira é lugar vibrante, vivo, efervescente, onde a qualquer momento a estabilidade pode ser rompida. Esse é o nosso lugar! O lugar do pesquisador de fronteira!

Fronteira é o que está à frente, tem a ver com o front - que se traduziu em um sentido de batalha, muitas vezes. Logo, o que marca a fronteira é justamente a sua capacidade de fricção, de atrito, de porosidade, o que faz passar, o que se negocia. Podemos pensar fronteiras como projeto e projeto como algo não dado, não delimitado, mas tecido, feito e refeito, negociado.

Fronteira não se confunde com limite. Limite demarca o fim de um território, por exemplo. A fronteira não é um fim, um ponto de limite. Ao contrário, é o lugar da negociação, do plano da política, tomada no sentido da composição - sempre negociada - de um mundo, composição de verdades contingentes. Um arranjo que posiciona o que conta e o que não conta no mundo, momentaneamente, porque é sempre permeável; mesmo que se objetive fazer parecer um mundo imutável.

Para Donna Haraway (2000), quando transgredidas as fronteiras, potentes fusões e perigosas possibilidades se formam. Podem significar realidades sociais e corporais vividas, nas quais a luta política consiste em ver a partir de ambas as perspectivas ao mesmo tempo, porque cada uma delas revela inimagináveis possibilidades e combinações (p. 51).

Fronteiras transgredidas e potentes fusões podem acontecer quando saberes frequentemente locais se esbarram, se atritam, negociam e amalgamam, se mesclam produzindo um novo estilo de pensar e trabalhar sobre um assunto.

O deslocamento daquilo que parece estável, já dado, naturalizado para uma nova conformação, quer seja no conhecimento sobre algo, quer seja sobre as técnicas utilizadas a partir do conhecimento sobre algo, leva à modificação das estruturas e estratégias praticadas anteriormente; portanto, desestabiliza. Como efeito, a modificação 
afeta, inquieta, desassossega o estabelecido e por isso produz perigosas possibilidades. Possibilidades de polifonia, de ter de ouvir todas as vozes, de encontros inusitados e transgressores, encontros de condições potentes.

Dessa maneira, foi possível perceber que outras gramáticas sobre a saúde foram escritas nestes últimos trinta anos em que vivi na fronteira. Traduções possibilitaram pontes negociáveis politicamente, e o diálogo de fronteira possibilitou a entrada das terapias diferenciadas da biomedicina no serviço de saúde pública do Brasil. Não se sabe, ainda, se tais terapias estão agindo dentro de uma cosmovisão filosoficamente tradicional, no entanto, de qualquer modo, existe algo de diferente (seria um vírus?) implantado na biomedicina, algo que transpassou a fronteira e produzirá algum efeito em ambos, que sobrevirá em outras gramáticas.

Portanto, estar na fronteira transgredida da saúde pública, na entrada das terapias naturais, integrativas e complementares no sistema de saúde público brasileiro, propõe olhar para modelos de saúde e cuidado originários de outras culturas e cosmovisão - medicina chinesa, a medicina ayurvédica e a homeopatia -, indica alguma controvérsia ao modelo que parecia estável, a biomedicina. Desde 2006, o Ministério da Saúde brasileiro, através do documento Política Nacional das Práticas Integrativas e Complementares - PNPIC, considera que o desenvolvimento da PNPIC no SUS é um aprofundamento do cuidado em saúde, em busca da integralidade da atenção, acesso a serviços e exercício da cidadania (Barros, Siegel \& Simoni, 2007).

Sendo assim, toda tradução implica uma traição...

\section{Transgressão de fronteiras do oriente para o ocidente}

No contexto sócio-histórico da saúde, a transgressão de fronteiras entre Oriente e Ocidente se deu em meio a questões de guerras. Ao final da dinastia Qin (1644-1911), início do século XX, a China, enfraquecida por duas guerras contra a Inglaterra (Guerra do Ópio), cedeu ao poder militar e aos novos valores culturais impostos pelo vencedor, valores ocidentais. Isso gerou a introdução da medicina ocidental e a proibição temporária da acupuntura na China. Momento em que foram implantadas as primeiras faculdades de medicina ocidental (biomedicina) no país. Segundo Tesser (2010), a medicina tradicional chinesa (MTC) foi trazida ao Brasil por imigrantes orientais, alguns chineses autorizados por D. João VI em 1812 e mais fortemente no início do século XX, entre 1910 e 1914 (14 mil imigrantes orientais) e entre 1925 e 1935 (mais de 140 mil imigrantes orientais). Esses orientais se instalaram e cultivaram sua cultura e modos de praticar cuidados em saúde (p. 127). 
No Brasil, entre as décadas de 1960 e 1970, o advento da contracultura fez despertar inúmeros "terapeutas dos pés descalços", codinome atravessado pela referência dos "médicos dos pés descalços" chineses. Os "médicos dos pés descalços" eram terapeutas orientais, camponeses, da China pós-revolução de 1966, que cuidavam da saúde da sua comunidade e não tinham formação acadêmica, pois recebiam ensinamentos sobre cuidados na forma tradicional: oralmente, de mestre para discípulo. Tais terapeutas tiveram um papel importante na sociedade chinesa, porque estavam mais próximos das comunidades e conseguiam manter uma referência cultural de cuidado em saúde, com base nas técnicas milenares das práticas orientais de saúde. Os "terapeutas dos pés descalços" brasileiros ficaram conhecidos posteriormente como "terapeutas alternativos" e conviveram em constante tensão com a medicina ortodoxa, como vimos no início do texto (Jayasuriya, 1996; Barros, Siegel \& Simoni, 2007; Tesser, 2010).

No caminho do uso dessas práticas em saúde, mudanças ocorreram nos termos "alternativo", "integrativo" e "complementar". Segundo Barros (2000), o que se verifica é que, a partir da década de 1980, se justificava como terapia "complementar", no âmbito da mediação política, aquilo que deixava de ser "alternativa", ou seja, deixava de haver a conjunção "ou" e passava-se a conjunção "e". Onde o que complementa não se opõe a priori. Passou a ser um grupo de "racionalidades médicas" 9 e de cuidado em saúde, práticas e produtos que não necessariamente fazem parte da biomedicina, mas que podem ser utilizadas como práticas terapêuticas que complementam os tratamentos da medicina ortodoxa.

\section{Na fronteira a tensão entre o Tao e a Biomedicina}

A medicina tradicional chinesa (MTC) é originária da China e data de mais de 4 mil anos de conhecimento. Segundo Tesser (2010), tratase de um conjunto de saberes e técnicas, de filosofia e visão de mundo derivados de uma cultura antiga. A MTC foi desenvolvida por meio da soma das experiências e observações clínicas feitas por muitas gerações de sábios e curadores tradicionais chineses. Um aspecto teórico fundamental é a ideia vitalista de que a energia organiza a matéria. A ideia taoista de que tudo contém a energia yin (feminina, fria) e a energia yang (masculina, quente), um contendo o germe do outro, e, no movimento dessas energias, quando se chega ao extremo de uma, se rompe na outra. Para Capra (1989), esse movimento vibratório contínuo produz vida e vitalidade, compõe a capacidade de viver, enquanto esse movimento estiver contínuo. Por vezes uma energia é mais forte do que a outra e isso mostra nuances e diferenças visíveis na natureza e na saúde do homem. 
Tais energias de potências diferentes estão nos alimentos (mais yin ou mais yang), no clima, nas cores, nos sons, nos pensamentos e estados emocionais, em todos os elementos da natureza. Para manter-se bem é preciso manter essa vibração em estados variáveis, evitando os bloqueios e os extremos. Parte-se do princípio de que o surgimento de um desequilíbrio provém de alguma crise do fluxo energético. Uma vez bloqueado em alguma parte do corpo, esse fluxo energético poderá ocasionar algum tipo de disfunção com efeitos. A partir de um bloqueio energético dos meridianos da acupuntura linhas que conduzem o fluxo energético -, organismo e funções que se localizam anteriores ao bloqueio sofrerão de pletora no sentido de excesso e irritação e, organismo e funções posteriores à linha do bloqueio energético sofrerão da insuficiência de energia vital ou hipofunção metabólica. $O$ enfraquecimento vital e seus efeitos ocorrerão antes mesmo de uma patologia. O bloqueio energético crônico trará o efeito de enfraquecimento do sistema autoimune (capacidade de reação ou energia ancestral) e o organismo se tornará terreno propício para uma invasão por um agente patogênico externo. Os agentes patogênicos internos são os pensamentos e os sentimentos.

A ênfase dessa racionalidade está no ser-humano doente, e não na doença. Dentro dessa proposta, o ser-humano é quem pode estar se sentindo bem, com boa qualidade de vida, desenvolvendo habilidades que não permitam insuficiência do fluido energético que circula em seu corpo ou práticas e habilidades que aumentem seu volume energético e assim o fortalecimento amplo.

Para Luz (2005), indubitavelmente as terapias alternativas possuem características de cuidados mais voltados para atenção e disponibilidade de tempo dedicado ao paciente, caracterizando maior facilidade para a meta de humanização do serviço. Ela explica que nos últimos tempos a humanização tem sido considerada um dos pontos do ethos - posicionamento ético-político - na condução dos processos de cuidado ${ }^{10}$. Ainda de acordo com Luz (2005), para atuar no cuidado em saúde baseado nas terapias naturais, integrativas e complementares é necessário ouvir atentamente as queixas, tocar o paciente, já que muitas terapêuticas usam técnicas de relaxamento e conforto corporal, e acompanhá-lo para os procedimentos terapêuticos semanalmente ou, pelo menos, mais de uma vez por mês, coisa que proporciona um vínculo forte de confiança e alívio do seu quadro, portanto, uma nova gramática para atender e cuidar de pessoas no serviço público de saúde (p. 147).

Os estudos do grupo de Madel Luz sobre as "racionalidades médicas" ${ }^{11}$ e as crises das ciências, as crises ecológicas do mundo apontadas por Boaventura Santos (2005) e muitos outros fatores parecem sustentar uma possível atitude mais democrática, dialogal e no espírito da complementaridade entre distintos saberes e ações em 
saúde (p. 85). No dizer de Santos (1982), é necessária uma segunda ruptura epistemológica, agora com a própria ciência, para que esta reencontre o senso comum e as outras tradições num movimento de mútuo enriquecimento, diferente da tradição teórica hegemônica nas ciências (p. 167).

A leitura que faço da sociologia da ciência é a que mais se adequa a tornar necessária e possível a dupla ruptura epistemológica. Deixou de ter sentido criar um conhecimento novo e autônomo em confronto com o senso comum (primeira ruptura) se esse conhecimento não se destinar a transformar 0 senso comum e a transformar-se nele (segunda ruptura). Fezse à hegemonia incondicional do saber científico e à consequente marginalização de outros saberes vigentes na sociedade, tais como o saber religioso, artístico, literário, mítico, poético e político. (...) aprendemos a sobreviver no mesmo processo e medida em que deixamos de saber viver (Santos, 1982, p. 169).

Para Santos (2005), hoje não se trata tanto de sobreviver e sim de saber viver. A incerteza do conhecimento, que a ciência moderna sempre viu como limitação técnica destinada a sucessivas superações, transforma-se na chave do entendimento de um mundo que mais do que controlado tem de ser contemplado. A criação científica do paradigma emergente se aproxima da criação literária ou artística, do escultor a trabalhar a pedra, subordinado à contemplação da obra de arte (p. 86).

No caminho do acolhimento das terapêuticas naturísticas como benéficas ao cuidado em saúde no SUS, Tesser (2010) chama a atenção para uma grande dificuldade no Brasil, assinalando que talvez não haja atores ou instituições bem estabelecidos e vinculados a outras racionalidades médicas ou tradições de cura em número significativo e ao mesmo tempo convergentes com o ideário do SUS e da promoção da saúde, para serem, de pronto, parceiros a serem reconhecidos e valorizados como referências para práticas complementares e outras racionalidades médicas, formadores de praticantes para sua oferta no SUS. No entanto, aspira que diversificar o processo de validação e legitimação das práticas para além da ciência e da biomedicina torna possível democratizar o tema e politizá-lo. Orienta como uma das estratégias possíveis, fomentar ativamente, no SUS e na saúde coletiva, pesquisas, estudo, capacitação e oferta de saberes/técnicas presentes nas práticas complementares e racionalidades médicas convergentes com os valores da promoção da saúde (p. 1740). 


\section{Não existe tradução sem traição, então, toda relação inventa alguma coisa}

A tradução a princípio pode ser tomada como ato de produção das redes sociotécnicas. Mas jamais é completamente descontextualizada, designando, a cada estudo, uma variedade de processos e deixando de designar outros tantos. A tradução, para Latour (2000), é sempre interpretativa, é insaciavelmente curiosa, indiscreta a respeito dos posicionamentos diferenciais. Latour (2012a) percebe sensivelmente que a tradução não é um ator entre muitos, nem uma força por trás de todos os atores transportados por meio de um deles, mas uma conexão que transporta transformações; trata de uma relação que não transporta causalidade, mas induz dois mediadores à coexistência (p. 160). Segundo Mol (2010), os termos e textos que circulam na Teoria do Ator-Rede são dispositivos, traduzem e traem o que buscam analisar, afinam a sensibilidade dos seus leitores, afinam a sintonia do que está acontecendo aqui e ali. Os relatos para os pesquisadores da Teoria do Ator-Rede em Latour (2012b) registram diferenças, absorvem multiplicidades e reformulam-se a cada novo passo. Em vez de simplesmente transformar efeitos sem transformá-los, cada um dos pontos no texto pode se tornar uma encruzilhada, um evento ou a origem de uma nova translação ( $p$. 189).

Transladar do Oriente para o Ocidente conhecimentos culturais sobre saúde (também sobre qualquer outro campo) só é possível com traição, mediante um desmanche filosófico cultural da visão de saúde entre culturas completamente distintas.

Transladar do Oriente para o Ocidente conhecimentos culturais sobre saúde (também sobre qualquer outro campo) não é possível sem traição. Trata-se de visões filosófico cultural distintas de saúde entre culturas completamente diversas. Neste caso, outras conformações aparecerão como versões possíveis desta translação de conhecimento. Para a etóloga belga Vinciane Despret (2001), a versão, como tradução considera que um mesmo termo pode abrir uma quantidade de significações e fazer divergir os sentidos. Dado que em uma tradução, os termos na língua de chegada podem levar a diversos outros sentidos. Para a autora, há na tradução um duplo movimento de colocação em comparações, no seio de cada universo de sentidos possíveis sob o efeito que o outro induz. Traduzir, portanto, segundo o modo da versão, conduz a multiplicar as definições e a proliferar muitas histórias. Para o pesquisador de fronteira interessa multiplicar as outras versões, mais brasileiras, nem oriental, nem ocidental, mas, aquelas que traduzem como se faz saúde neste encontro.

Para isto, o que faz o jogo de fronteira é o olhar. Olhar não para o objeto isolado e sim para o projeto e os processos. Olhar não para 
ilhas com os seus limites e sim para as fronteiras e suas condições de permeabilidade passíveis de construção de pontes. Então, a objetividade na pesquisa passa a ser estar em conexão. Não se trata de só seguir, é seguir tecendo o projeto de fronteira, ou seja, seguir e se dar conta das controvérsias, recolher, seguir por outras linhas de fronteira e encontrar outros pontos que sejam mais permeáveis a construções de pontes. Seguir em meio ao caos, à crise, na fricção da fronteira, onde já não se é, encontrar no espaço livre a possibilidade de no extremo ser híbrido, ser outro, ter outra forma, outro modo de viver, de pesquisar. Segundo Boaventura Santos (2001), a subjetividade surge como o grande mediador entre conhecimentos e práticas possibilitando formular questões surpreendentes onde formas alternativas de conhecimento geram práticas sociais alternativas e vice-versa (p. 345). Dessa maneira, na fronteira entre conhecimentos e práticas surge a pergunta: como ser capaz de fazer conexões entre os coletivos quando, na maior parte das vezes, esses coletivos - incluindo os pesquisadores - funcionam como ilhas ensimesmadas com limites bem protegidos?

Pensamos, com Haraway (1995), que o relativismo e a totalização são, ambos, mitos comuns da retórica de uma Ciência (com letra maiúscula $=$ hegemônica) que impõe o conhecimento prometendo, igual e inteiramente, visão de toda parte e de nenhum lugar. Ao contrário, para nós a prática faz um jogo de encenação gerado por um ambiente local colocado em cena. Afinal, como diz Latour (2001), a agudeza do pesquisador experimentador consiste em elaborar enredos alternativos e encená-los com cuidado, para que o actante participe de situações novas e inesperadas capazes de defini-lo ativamente (p.143).

O método de pesquisa, longe de apreender uma realidade, performa no sentido traduzido por Arendt e Moraes (2013) do termo enact utilizado por Mol (2002) para dizer que nenhum objeto existe sem estar articulado às práticas que o produzem e o fazem existir (p.314), ou seja, uma realidade colocando em cena o que conta ou não conta como objetividade e racionalidade. Para Márcia Moraes (2000), estudar a ciência em ação nos leva a um universo filosófico que não se confunde com o paradigma dualista típico do pensamento moderno, a ciência em ação se movimenta em um mundo cuja realidade é múltipla, um mundo de conexões possíveis de elementos díspares, só dizíveis na mestiçagem das bricolagens dos saberes ( $p$. 5).

A ideia de "racionalidade" para Mol (2008), atravessa o sentido da organização ou "modos de ordenar", que derivam mais de uma ação como verbo, um esforço contínuo, feito nas práticas, nas conexões, no suor para produção do real. Dessa maneira, para essa autora, o papel do cientista social é conseguir encontrar as "conexões" "locais" e "parciais" em busca da "racionalidade" que performa o campo. O 
cuidado está em fazer pequenos ajustes sem saber previamente aonde vai chegar; a finalidade não transcende a ação da própria prática. Sendo assim, mais de um modo é relevante em qualquer tempo e em qualquer espaço, e o pesquisador-cientista deve manejar esses modos de operar (p. 263).

Haraway (2000) aposta na transformação dos sistemas de conhecimento e nas maneiras de ver que essas coisas têm importância política, dizem respeito a ser múltiplo (p. 205).

Tentamos com essas racionalidades múltiplas aparentes no serviço público de saúde brasileiro desfamiliarizar a tradição canônica e hegemônica do saber e abrir espaço para o que não conta como objetividade para a Ciência; politicamente vivemos a pesquisa de fronteira, a mediação feita com conexões possíveis para uma coexistência de racionalidades não coerentes, caracterizando assim o olhar e a escrita barroca.

\section{Considerações finais}

$\mathrm{Na}$ bricolagem dos saberes ocorrem inúmeras tensões em fronteiras, onde, no extremo, escolhas são feitas e a ação da escrita maneja politicamente aquilo que conta. Para John Law (2004), o pesquisador escreve para manejar e fazer existir mundo. Portanto, há uma luta que se faz também na escrita, uma luta política, usando o recurso da escrita e atentando em cada palavra para intervir na existência do que conta. Nesse sentido, a escrita é encarnada, é nela que o autor escolhe o que, das múltiplas ofertas de possibilidade do campo, se tornará visível ou invisível, é na linguagem encarnada que se pode criar mundo e mundos podem ser criados pelo leitor (p. 25). a linguagem pode criar mundo e mundos podem ser criados pelo leitor. O maior é que nos constitui (Law 2004), fomos educados a crer na Grande Ciência, ela nos constitui; no entanto, para criarmos outros mundos, o pesquisador que resiste 0 arqueiro Zen, o nômade desterritorializado, traz a visão para o pequeno, o local, o parcial, o barroco, fugindo do engodo da visão do geral, daquela que faz desaparecer quando o assunto não interessa.

Com a análise do pequeno, aprendemos que é nas nuances que se encontra a complexidade. Quando deixamos de falar do geral, do voo panorâmico e superficial dos acontecimentos, tentamos modificar os modos de pesquisa e sua racionalidade presente. Tentamos escrever a vida por outras gramáticas.

Ocidentalizar formas de cuidados orientais colocando-os consumíveis para a cultura ocidental, traduzir um conhecimento oriental para uma vida ocidental só poderia ser feito com traição, produzindo novas versões. Necessariamente, traição não é algo ruim e sim, nos termos da TAR, algo que faz parte do processo. Esses novos conhecimentos 
e práticas transmutados em algo ainda não nominado é o que temos e já faz a maior diferença, pois complementa e faz pensar todos os envolvidos na saúde. A utilização de diferentes materiais (moxa, sementes de mostarda, óleos essenciais, agulhas de acupuntura, etc.) e diferentes procedimentos terapêuticos (acupuntura, shiatsu, tui-na, reflexoterapia, auriculoterapia, reiki, etc.) ressoam como novas traduções de saúde e de cuidado em saúde. Os fundamentos ontológicos da medicina chinesa, ayurvédica e da homeopatia alemã são performados na crença da energia circulante, por dentro e por fora, do céu e da Terra em todos os elementos existentes no Universo e mundos. Isso dentro do sistema público de saúde cria uma tensão interessante entre práticas de cuidado e de pensar saúde. Nesse caminho, para Latour (2012a), a tradução é efetuada com rodeios que modificam o objeto inicial e compõe uma nova ação coletiva ( $p$. 36).

Um profissional postado ao lado de uma maca com um bastão de moxa (Artemisia vulgaris em rolo para aquecer o ponto de acupuntura) em brasa na mão, aproxima a moxa da pele do usuário deitado na maca. Tal aproximação, a menos de dez milímetros do contato com a pele, cria uma espécie de tensão - entre se deixar levar pelo calor curativo e o medo de ser queimado. Momento de fronteira, fricção e negociação.

Nessa fronteira, entre a pele e a moxa em brasa, acontece a possibilidade de uma luta entre corpos que dançam uma escritura ainda não traduzida. Uma zona de fronteira à espera do que virá a ser, onde nem mais se pertence ao território de origem e nem se é aceito pelo novo território, um estado de transição, que poderá durar muito tempo, que não se sabe ainda, mas que convoca a negociações, a novas possibilidades de escrita.

\section{Referências}

Amaral, L (2000). Carnaval da alma: comunidade, essência e sincretismo na Nova Era. Petrópolis: Vozes.

Arendt, R., e Moaraes, M, (2013). Mol e psicologia social. Psicologia em Estudo, 18(2), p. 313-321.

Barros, N. F.; Siegel, P., \& Simoni, C. (2007). Política Nacional de Práticas Integrativas e Complementares no SUS: passos para o pluralismo na saúde. Cad. Saúde Pública, 23(12), 3066-3067.

Barros, N. F. (2000). Medicina Complementar: uma reflexão sobre o outro lado da prática médica. São Paulo: Annablumer. FAPESP.

Constituição da República Federativa do Brasil. (1988). Brasília: Senado Federal.

Capra. F. (1989). O tao da física (2a ed.), São Paulo: Cultrix. 
Carvalho, A.C.D. (2005). Feiticeiros, burlões e mistificadores: criminalização e mudança das práticas populares de saúde em São Paulo, de 1950 a 1980. São Paulo: Editora UNESP.

Deleuze. G. (1995). Introdução: Rizoma. Mil platôs- Capitalismo e esquizofrenia. São Paulo: Editora 34.

Deleuze, G. \& Guattari, F. (1997). Mil platôs - capitalismo c esquizofrenia, (vol. 5); (Peter PálPelbart \& Janice Caiafa, Trads.). São Paulo: Editora 34.

Deleuze, G., \& Parnet, C. (1998). Diálogos. (Eloisa Araújo Ribeiro, Trad.). São Paulo: Escuta.

Despret, V. (2001). Ces émotions qui nous fabriquent: ethnopsychologie des émotions. Paris: Les Empêcheurs de Penser en Ronde/ Le Seuil.

Eckersley, C. E.; Macaulay, M. (1955). Brighter Grammar. London: Longsman, Green \& Co. Ltd.

Ferreira, A. B. de H. (1999). Aurélio século XXI (3a ed.). Rio de Janeiro: Nova Fronteira.

Foucault, M. (1979). A microfísica do poder (Roberto Machado, Trad.). Rio de Janeiro: Edições Graal.

Haraway, D. (1995). Saberes Localizados: a questão da ciência para o feminismo e o privilégio da perspectiva parcial. Cadernos Pagu, 5. Campinas: Ed. Unicamp.

Haraway, D. (2000). Antropologia do Ciborgue - as vertigens do póshumano. Belo Horizonte: Autêntica.

Herrigel, E. (1999). A arte cavalheiresca do arqueiro zen. São Paulo: Ed. Pensamento.

Jayasuria, A., \& Bastos, S. (1966). Alternativas em Saúde. Rio de Janeiro: Sohaku-in Edições.

Latour, B. (2000). Ciência em ação: como seguir cientistas e engenheiros sociedade afora. São Paulo: UNESP.

Latour, B. (2001). A esperança de Pandora: ensaios sobre a realidade dos estudos científicos. Bauru: EDUSC.

Latour, B. (2012a). Cogitamus: seis cartas sobre las humanidades científicas. Argentina: Paidós Espaço del Saber.

Latour, B. (2012b). Reagregando o social: uma introdução à teoria do Ator-Rede. Salvador: EDUFBA-EDUSC.

Law, J. (2004). After Method: Mess in Social Science Research. New York: Taylor \& Francis.

Luz, M. (1988). Natural, Racional, Social Razão Médica e Racionalidade Científica Moderna. Rio de Janeiro: Ed. Campus.

Luz, M. (2005).Cultura contemporânea e medicinas alternativas: novos paradigmas em saúde no fim do século XX. Revista de Saúde Coletiva, Physis, 15. Rio de Janeiro.

Mol, A. (2002). The body multiple. Ontology in Medical Practice, Durhan, NC: Duke Univercity Press.

Mol, A. (2008). The logic of care, Amsterdan. 
Mol, A. (2010). Actor-Network Theory: Sensitive Terms and Enduring Tensions. KölnerZeltschriftfürSoziologie und Sozialpsychologie, 50(1), 253-269.

Moraes, M. (2000). O conceito de rede na filosofia mestiça. Revista Informare, 6(1), 12-20.

Política Nacional de Práticas Integrativas e Complementares do SUSPNPIC (2006).

Programa de Promoção do Desenvolvimento da Faixa de Fronteira PDFF, Ministério da Integração Nacional (2007).

Santos, B. S. (1982). Introdução a uma ciência pós-moderna. Rio de Janeiro: Editora Campus.

Santos, B. S. (2001). A Crítica da Razão Indolente. Volume 1. PortoPT: Edições Afrontamento.

Santos, B. S. (2002). Democratizar a democracia: os caminhos da democracia participativa. Rio de Janeiro: Civilização brasileira.

Santos, B. S. (2005). Um discurso sobre as ciências (3a ed.), São Paulo: Cortez.

Stangers, I. (1998). Power and invention: Situating Sciency, Minneapolis: University Mimnesota Press.

Tesser, C. D.(2010). (Org.) Medicinas Complementares: o que é necessário saber (Homeopatia e Medicina Tradicional Chinesa/Acupuntura). São Paulo: Editora UNESP.

\section{Endereço para correspondência \\ Maria Aparecida dos Santos}

Universidade Federal Fluminense

Programa de Pós-Graduação em Psicologia Social - Campus do Gragoatá

Rua Prof. Marcos Waldemar de Freitas Reis, s/n bloco O sala 214, Gragoatá, CEP

24210-201, Niterói - RJ, Brasil

Endereço eletrônico: irisapa@hotmail.com

Recebido em: 12/05/2014

Reformulado em: 17/09/2014

Aceito para publicação em: 29/09/2014

\footnotetext{
Notas

* Doutoranda do Programa de Pós-Graduação em Psicologia Social da Universidade Federal Fluminense, Niterói-RJ, Brasil.

1 Esta é uma proposta do Grupo de Pesquisa "Pesquisar Com", primeiramente proposta pela Professora Márcia Moraes da Universidade Federal Fluminense (UFF), da cidade de Niterói (RJ), Brasil.

2 Doutorado do Programa de Pós-Graduação em Psicologia Social da Universidade Federal Fluminense com o título (autor, 2012).

${ }^{3}$ Bruno Latour (2001) esclarece que, ator é tudo que age, deixa traço, produz efeito no mundo, podendo se referir a pessoas, instituições, coisas, animais, objetos, máquinas. Ator não se refere apenas aos humanos, mas também aos não humanos. Por esse motivo Latour (2001) sugere o termo actante: “(...) uma vez que, em inglês, a palavra actor (ator) se limita a humanos, utilizamos muitas vezes actant (actante), termo tomado à semiótica para incluir não-humanos na definição" (p. 346).
} 
4 Sociedade de Homeopatia do Estado do Rio de Janeiro, professor convidado do Curso de Formação de Especialistas em Homeopatia da SOHERJ ministrando (autor, 1991).

$5 \mathrm{~V}$ Congresso Internazionale di Iridologia, "Iridologia e Psicossomática" e "Influência do padrão transgeracional nos sinais iridológicos". DO.RI.MO Centro de Documentazione e Ricerca in Microsemeiotica Oftalmica, Montegrotto Terme (Padova - Italia), (autor, 2002).

${ }^{6}$ Biblioteca Virtual da Saúde.

${ }^{7}$ Dissertação de mestrado (autor, 2011).

8 Para Foucault "todo saber é político"; a arqueologia foucaultiana faz pensar que todo conhecimento só pode existir a partir de condições políticas que são as condições para que se formem tanto o sujeito quanto os domínios do saber. Saber e poder se implicam mutuamente, e todo saber constitui novas relações de poder (Foucault, 1979, p. XXI). Foucault (1988) nos sugere que "lá onde há poder há resistência e por isso mesmo esta nunca se encontra em posição de exterioridade em relação ao poder. Não existe, com respeito ao poder, um lugar da grande Recusa, mas sim resistências, no plural, espontâneas, selvagens, solitárias, planejadas, arrastadas, violentas, prontas ao compromisso, interessadas ou fadadas ao sacrifício; por definição não podem existir a não ser no campo estratégico das relações de poder (p. 91).

9 "Racionalidades médicas" é uma expressão empregada pela socióloga Terezinha Madel Luz que, desde 1991, dirige um grupo de pesquisa com esse nome, do CNPq, no IMS-UERJ e, hoje em dia, no Huap/Niterói, promovendo estudos sobre paradigmas, saberes e sistemas complexos tradicionais de saúde que possuem sua própria racionalidade tais como: medicina chinesa, homeopatia, medicina ayurvédica, entre outros.

10 Para pensar a noção de contracultura, pois esta não se estabelece como um advento claro e definido e sim uma releitura de uma época em que determinadas práticas sem grande coesão ocorreram, sugiro a leitura dos livros Carnaval da alma: comunidade, essência e sincretismo, de Leia Amaral e Contracultura de Theorore Rozsak.

${ }^{11}$ Humanização vincula-se ao Ministério da Saúde e tem como proposta efetivar-se não como um programa, mas como uma política que atravessa as diferentes ações e instâncias gestoras do SUS, apostando na indissociabilidade entre os modos de produzir saúde e os modos de gerir os processos de trabalho, entre produção de saúde e produção de subjetividade, entre clínica e política (Brasil, 2009). Hyperlink http://dtr2004.saude.gov.br/dab/publicacoes. php 